\title{
SOLICITAÇÃO DE REFÚGIO EM FAVOR DE CRIANÇAS E ADOLESCENTES DESACOMPANHADOS(AS): A ATUAÇÃO DA DEFENSORIA PÚBLICA DA UNIÁO
}

\author{
REFUGE REQUEST FOR UNACCOMPANIED CHILDREN AND ADOLESCENTS: THE ROLE OF \\ THE FEDERAL PUBLIC DEFENDER'S OFFICE
}

Gabriel de Oliveira Silva

Bacharel em Direito, Universidade Presbiteriana Mackenzie Analista Técnico Administrativo, DPU/SP

gabriel.osilva@dpu.def.br

\section{RESUMO}

O aumento no número de pedidos de refúgio e do fluxo migratório em geral trouxe novos desafios para a Defensoria Pública da União. Um destes desafios se relaciona com o tratamento que deve ser dado pelo Defensor Público às crianças e adolescentes migrantes desacompanhados em território nacional de seu responsável legal. Como forma de dar solução a este problema, o Conanda, o Conare, o Cnig e a DPU editaram resolução conjunta estabelecendo procedimentos para a regularização migratória, principalmente através do pedido de refúgio, e medidas de proteção a este grupo específico de imigrantes. $\mathrm{O}$ presente artigo visa analisar a referida resolução, bem como verificar a natureza e legitimidade da atuação da Defensoria Pública da União em favor de crianças e adolescentes desacompanhados.

Palavras-chave: Crianças e adolescentes. Refúgio. Regularização. Proteção.

\begin{abstract}
The increase in the number of requests for refuge and the migratory flow in general has brought new challenges for the Federal Public Defender's Office. One of these challenges is related to the treatment that should be given by the Public Defender to migrant children and adolescents unaccompanied in the national territory of their legal responsible. As a way of solving this problem, Conanda, Conare, Cnig and DPU published resolution establishing procedures for the immigration regulation, mainly through the request for refuge, and protective measures for this specific group of immigrants. This article aims to analyze this resolution, as well as verify the nature and legitimacy of the action of the Federal Public Defender's Office in favor of unaccompanied children and adolescents.
\end{abstract}

Keywords: Children and adolescents. Refuge. Regularization. Protection.

Dara de submissão: 15/02/2018

Data de aceitação: 03/12/2018 


\section{SUMÁRIO}

INTRODUÇÃO. 1. A LEGITIMIDADE DA DEFENSORIA PÚBLICA PARA PROTEÇÃO DOS DIREITOS HUMANOS E DOS DIREITOS DAS CRIANÇAS E ADOLESCENTES. 2. O REFÚGIO NO BRASIL E A DEFENSORIA PÚBLIÇA DA UNIÃO. 3. A RESOLUÇÃO CONJUNTA ENTRE CONARE, CONANDA, CNIG E DPU E A NATUREZA DA ATUAÇÃO DO DEFENSOR PÚBLICO FEDERAL. CONSIDERAÇÕES FINAIS.

\section{INTRODUÇÁO}

Nos últimos tempos, o tema refúgio ganhou espaço nas notícias dos principais meios de comunicação. Tendo em vista o grande fluxo migratório decorrente dos mais diversos problemas humanitários e econômicos, o mundo se deparou com uma problemática até então quase oculta: a "crise migratória mundial".

Para além de um problema global que é tratado tão somente por vias diplomáticas, a realidade demonstra que o sistema da Justiça tem, de igual modo, enfrentado a temática refúgio. ${ }^{2}$

Em 2012, o Brasil recebeu mais de duas mil solicitaçôes de refúgio. Dentre elas, 148 (cento e quarenta e oito) eram solicitaçôes de crianças ou adolescentes. Deste total, quatorze estavam sem representantes no Brasil. ${ }^{3}$

Já em 2016,18\% dos beneficiados com status de refugiado eram pessoas entre 0 e 17 anos. ${ }^{4}$

Mundialmente, segundo dados da Alto Comissariado das Naçóes Unidas para Refugiados (Acnur), em 2014, mais da metade da população de refugiados eram crianças, sendo trinta e quatro mil crianças separadas (acompanhadas de adultos que não são os representantes legais) ou desacompanhadas. ${ }^{5}$

\footnotetext{
$1 \quad$ Vide: https://noticias.uol.com.br/ultimas-noticias/deutschewelle/2018/01/30/lideres-da-austria-e -hungria-pedem-fim-da-imigracao-ilegal.htm; e http://br.rfifr/europa/20180119-londres-e-paris-assinam-acordo-para-atenuar-crise-migratoria-em-calais.

2 BASTOS, C. E. C.; GARCIA, M. Judiciário pode rever decisão que deu refúgio a Battisti. 10 de março de 2009. Disponível em: < https://www.conjur.com.br/2009-mar-10/judiciario-rever-decisao-ministerial-deu-refugio-battisti>.

3 MARTUSCELLI, P. N. A Proteção Brasileira para crianças refugiadas e suas consequências. In: REMHU: Revista Interdisciplinar da Mobilidade Urbana, 2014.

4 VALlE, M. F. V. O Processo de Refúgio no Brasil e a Proteção à Criança Solicitante de Refúgio. In: Revista Eletrônica de Direito Internacional. Edição Especial - Refugiados, 2017, p. 3.

VALLE, Op. Cit., p. 3.
} 
Por razóes óbvias, este grupo migrante vulnerável acaba por atracar suas esperanças no órgão público constitucionalmente responsável pela proteção jurídica de minorias: a Defensoria Pública.

Nos grandes centros nacionais de imigrantes, a demanda da Defensoria Pública relacionada à regularização migratória e solicitação de refúgio acaba por ser tão destacada quanto às demais. A quantidade de casos apresentados à Defensoria Pública da Uniāo justificou, inclusive, a criação de três ofícios especializados em migração e refúgio na unidade de São Paulo, maior capital brasileira e ponto focal do fluxo migratório nacional. ${ }^{6}$

Com o contato mais próximo da Defensoria Pública com este grupo específico, alguns problemas práticos vieram à tona. Um deles, bastante específico, chamou a atenção da DPU: como tratar casos de crianças e adolescentes que precisam solicitar refúgio, mas chegam ao país sem acompanhamento dos pais ou responsáveis?

Sem dúvida, o impasse jurídico é profundo. Temos de um lado, pessoas notadamente vulneráveis que precisam se regularizar em território nacional, apresentando seu caso ao órgão administrativo competente. De outro temos a completa ausência de representante legal segundo a legislação civil brasileira, o que trouxe a negativa expressa da Polícia Federal, órgão responsável pelo recebimento de pedidos de refúgio no Brasil, em receber as solicitaçóes das crianças e adolescentes, já que estas não têm capacidade jurídica para tanto.

A questão foi solucionada com uma resolução conjunta entre diversos órgãos do Poder Público que trouxe a possibilidade de o Defensor Público Federal realizar o pedido administrativo e se tornar, de certa forma, temporariamente responsável pela criança ou adolescentes solicitante de refúgio.

Este artigo pretende analisar de forma sucinta a natureza da atuação da Defensoria Pública da União em favor destas crianças e adolescentes.

\title{
1. A LEGITIMIDADE DA DEFENSORIA PÚBLICA PARA PROTEÇÁO DOS DI- REITOS HUMANOS E DOS DIREITOS DAS CRIANÇAS E ADOLESCENTES
}

Conforme o art. 134 da Constituição Federal:

\begin{abstract}
A Defensoria Pública é instituição permanente, essencial à função jurisdicional do Estado, incumbindo-lhe, como expressão e instrumento do regime democrático, fundamentalmente, a orientação jurídica, a promoçáo dos direitos humanos e a defesa, em todos os graus, judicial e extrajudicial, dos direitos individuais e coletivos, de forma integral e gratuita, aos necessitados, na forma do inciso LXXIV do art. $5^{\circ}$ desta Constituiçáo Federal. ${ }^{7}$
\end{abstract}

\footnotetext{
6 BRASIL. Sítio oficial da Defensoria Pública da Uniáo. Disponível em: $<$ http://dpu.def.br/endereco-sao-paulo\#faqnoanchor>.

7 BRASIL. Constituiçáo da República Federativa. 1988.
} 
Com a redação dada pela emenda constitucional no 80 de 2014, cristalizou-se a verdadeira transformação da Defensoria Pública. O órgão passou de "advogado dos pobres" para instituição protetora dos direitos humanos em geral. Tal alteração constitucional foi realizada tão somente para ratificar o que a Defensoria Pública já tinha se tornado: ombudsman dos hipossuficientes e vulneráveis.

\section{Segundo Sarmento ${ }^{8}$ :}

Destaque-se que a Federación Iberoamericana del Ombudsman - FIO define o instituto como "uma instituição pública (criada normalmente pela Constituiçáo e regulada por lei do Parlamento) dotada de autonomia, cuja finalidade principal é proteger os direitos humanos dos cidadãos frente à Administração Pública do país respectivo".

Nesses termos, não resta dúvida de que a Defensoria Pública da União exerce função de ombudsman. Como visto, trata-se de entidade autônoma, dotada de estatura constitucional, cujas funçóes institucionais abrangem "a promoção dos direitos humanos e a defesa, em todos os graus, judicial e extrajudicial, dos direitos individuais e coletivos, de forma integral e gratuita, aos necessitados" (art. 134, caput, CF).

Portanto, por imposição constitucional, cabe à Defensoria Pública a proteção dos direitos humanos. Entendemos pertinente tal atribuição à Defensoria Pública, tendo em vista que é esta instituição que lida direta e diariamente com o leque social que mais sofre com as mais variadas formas de violação de direitos humanos.

Com este mesmo entendimento, Barros $^{9}$ afirma que:

[...] foi expressamente incluído no dispositivo a missão da Defensoria de promover direitos humanos. Essa alteração faz parte de um movimento político-legislativo já bastante claro de priorizaçáo da tutela dos direitos humanos. [...] Mais uma vez, assim como na consolidação do regime democrático, a Defensoria Pública tem papel relevante na promoção dos direitos humanos, pois é a Instituição que lida diariamente com aqueles que mais sofrem com a violação de seus direitos. [Grifos do autor]. 
Assim, não mais prevalece o antigo entendimento de que o papel da Defensoria Pública é única e exclusivamente o patrocínio de açóes judiciais em favor do pobre. Portanto, perfeitamente possível a intervenção da Defensoria Pública em favor do refugiado, tendo em vista o nítido caráter humanitário do instituto, conforme veremos no próximo capítulo.

E não é diferente na prática. A Defensoria Pública da União se consolidou como instituição referência no atendimento e proteção a migrantes e refugiados. Apesar da inexistência de dados sobre a quantidade de atendimentos realizados pela DPU na matéria, temos que a atuação do órgão tem sido ostensiva. Podemos citar, como exemplo, a atuação do órgão defensorial nas seguintes oportunidades: regularização migratória dos índios venezuelanos Warao no Amazonas; a ação civil pública para isenção de taxas a migrantes hipossuficientes; pedido de regularização migratória coletiva de imigrantes do Rio Grande do Sul; ajuizamento de ação civil pública para anulação de multas aplicadas contra crianças e adolescentes migrantes por estada regular em território nacional; proteção de migrantes detidos no "corredor" do Aeroporto de Guarulhos/SP. ${ }^{10}$

Como desdobramento do próprio dever de proteção aos direitos humanos, a Defensoria Pública ganhou, entre outras, a atribuição de proteção aos direitos das crianças e adolescentes. Conforme disposição expressa da Lei Complementar no 80, organizadora da instituiçáo, é função institucional da Defensoria Pública:

exercer a defesa dos interesses individuais e coletivos da criança e do adolescente, do idoso, da pessoa portadora de necessidades especiais, da mulher vítima de violência doméstica e familiar e de outros grupos sociais vulneráveis que mereçam proteção especial do Estado; ${ }^{11}$

É importante observar que o Estatuto da Criança e Adolescente garante o acesso à Defensoria Pública a todas as crianças e adolescentes que dela necessitarem, estando em total sintonia com o disposto na LC80. ${ }^{12}$

Não à toa, recentemente, em pesquisa realizada pelo Conselho Nacional do Ministério Público, a Defensoria Pública foi considerada a instituição mais relevante na proteção de crianças e jovens, além de ser, segundo os brasileiros, a instituição mais importante do Brasil. ${ }^{13}$

Voltando ao tema do presente artigo, estamos diante de uma dupla atribuição da Defensoria Pública: atuação em favor de refugiados como instituição protetora dos direitos humanos e atuação em favor de crianças e adolescentes, por expressa disposição legal.

10 BRASIL. Defensoria Pública da União. Anuário de Atuação Coletiva da Defensoria Pública da União. Abril 2017 - Maio 2018. 2018, p. 49-51.

11 BRASIL. Lei Complementar no 80, de 12 de Janeiro de 1994. Organiza a Defensoria Pública da Uniáo, do Distrito Federal e dos Territórios e prescreve normas gerais para sua organizaçáo nos Estados, e dá outras providências. Art. $4^{\circ}$, inciso XI.

12 BRASIL. Lei no 8.069, de 13 de julho de 1990. Dispóe sobre o Estatuto da Criança e do Adolescente e dá outras providências. Art. 141 .

13 BRASIL. Conselho Nacional do Ministério Público. Relatório da Pesquisa de Satisfação e Imagem do CNMP e do Ministério Público, Julho de 2017. 
Existe, assim, uma intersecção entre estes dois grupos vulneráveis, demonstrando a clara legitimidade da Defensoria Pública na atuação em favor de crianças e adolescentes solicitantes de refúgio desacompanhados de seus responsáveis legais.

\title{
2. O REFÚGIO NO BRASIL E A DEFENSORIA PÚBLICA DA UNIÁO
}

O instituto do refúgio foi regulamentado com a Convenção Relativa ao Estatuto dos Refugiados de 1951. Em um primeiro momento, a Convenção trazia uma limitação temporal ao conceito de refugiado dispondo que seria considerado refugiado aquele

\begin{abstract}
Que, em consequência dos acontecimentos ocorridos de $1^{\circ}$ de janeiro de 1951 e temendo ser perseguida por motivos de raça, religiáo, nacionalidade, grupo social ou opinióes políticas, se encontra fora do país de sua nacionalidade e que náo pode ou, em virtude desse temor, não quer valer-se da proteçáo desse país, ou que, se não tem nacionalidade e se encontra fora do país no qual tinha sua residência habitual em consequência de tais acontecimentos, náo pode ou, devido ao referido temor, não quer voltar a ele. ${ }^{14}$
\end{abstract}

O refúgio surgiu, portanto, de uma tentativa de proteção àqueles que migraram em decorrência das diversas atrocidades da Segunda Guerra Mundial.

Porém, o temor de perseguição não acabou após o término da guerra. Até os dias atuais, diversas pessoas saem de seus países de origem em decorrência de perseguiçóes e violaçóes de direitos humanos. Esta situação levou à edição, em 1966, de um Protocolo ao Estatuto dos Refugiados que reconhece que "surgiram novas categorias de refugiados desde que a Convenção foi adotada e que, por isso, os citados refugiados não podem beneficiar-se da Convenção". ${ }^{15}$

Assim, tal protocolo excluiu a limitação temporal disposta na redação original da Convenção de Refúgio, dispondo que qualquer pessoa que se enquadre no conceito de refugiado deve ter a proteção do Estado, independentemente de o temor ser proveniente das situaçóes da Segunda Guerra Mundial. ${ }^{16}$

\footnotetext{
14 BRASIL. Decreto no 50.215, de 28 de janeiro de 1961. Promulga a Convençáo relativa ao Estatuto dos Refugiados, concluída em Genebra, em 28 de julho de 1951.

15 BRASIL. Decreto no 70.946 de 7 de agosto de 1972. Promulga o Protocolo Sobre o Estatuto dos Refugiados. Preâmbulo.

16 In verbis: "Para fins do presente Protocolo o termo 'refugiados', [...] significa qualquer pessoa que se enquadre na definição dada no artigo primeiro da Convenção, como se as palavras 'em decorrência dos acontecimentos ocorridos antes de $1^{\circ}$ de janeiro de 1951 e...' e as palavras '... como consequência de tais acontecimentos’ não figurassem do parágrafo 2 da seçáo A do artigo primeiro”.
} 


\section{Conforme André de Carvalho Ramos: ${ }^{17}$}

Inicialmente, a Convenção possuía uma limitação temporal (para acontecimentos ocorridos antes de $1^{\circ}$ de janeiro de 1951) e geográfica da definiçáo de refugiado (somente para os eventos ocorridos na Europa).

Em 1967, foi adotado o Protocolo sobre o Estatuto dos Refugiados, que eliminou tais limitaçóes. Esse Protocolo foi firmado com a finalidade de se aplicar a proteção da Convenção a outras pessoas que não apenas aquelas que se tornaram refugiadas em resultado de acontecimentos ocorridos antes de $1^{\circ}$ de janeiro de 1951 . O texto do Protocolo possui onze artigos, dentre os quais aquele que prevê a cooperaçáo das autoridades nacionais com o Alto Comissário das Naçóes Unidas para os Refugiados e seu dever de fornecer informaçóes e dados estatísticos sobre a condição de refugiados, a aplicaçáo do Protocolo e sobre as leis, regulamentos e decretos que possam vir a ser aplicáveis em relação aos refugiados (artigo II).

\section{Ainda, Reis e Menezes ${ }^{18}$ lecionam:}

O regime internacional dos refugiados pode ser definido como o conjunto de normas, leis e instituiçốes desenhado para proteger e assistir os migrantes forçados que cruzaram uma fronteira internacional devido ao medo de perseguição ou - conforme instrumentos regionais - devido à violência generalizada em seus próprios países, agressão estrangeira, conflitos internos ou violaçáo massiva de direitos humanos. Essa estrutura tem como base a definição de refugiado presente na Convenção Relativa ao Estatuto do Refugiado, de 1951 (parcialmente alterada por seu Protocolo Relativo de 1967); sendo, ainda, configurada pela atuação do Alto Comissariado das Naçóes Unidas para os Refugiados (Acnur), da Agência das Naçóes Unidas de Assistência aos Refugiados Palestinos no Oriente Próximo (UNRWA, sigla em inglês) e de organizações não-governamentais nacionais e internacionais, assim como a dos Estados que aderiram ou agem de acordo com os instrumentos internacionais que versam sobre a questão. $\mathrm{O}$ instituto de refúgio que vige na atualidade, portanto, resulta de uma concertação internacional que compreendeu ser a cooperação internacional o modo mais adequado para lidar com esse tipo de migração internacional forçada.

17 RAMOS, A. de C. Curso de Direitos Humanos, 2014, p. 157.

18 REIS, R. R.; MENEZES, T. S. Direitos Humanos e refúgio: uma análise sobre o momento anterior à determinação do status de refugiado. In: Revista de Sociologia e Política, 2014. 
Convém, ainda, destacar uma breve diferenciação entre o instituto do refúgio e o asilo político. Flávia Piovesan nos ensina que:

O refúgio é um instituto jurídico internacional, tendo alcance univer-
sal e o asilo é um instituto jurídico regional, tendo alcance na região
da América Latina. O refúgio, como já examinado, é medida essen-
cialmente humanitária, enquanto o asilo é medida essencialmente po-
lítica. O refúgio abarca motivos religiosos, raciais, de nacionalidade,
de grupo social e de opinióes políticas, enquanto o asilo abarca apenas
crimes de natureza política. Para o refúgio basta o fundado temor de
perseguiçăo, enquanto para o asilo há a necessidade da efetiva perse-
guiçăo. ${ }^{19}$

Regulamentando a Convenção, o Brasil, em 1997, promulgou a Lei no 9.474, definindo critérios e procedimentos para a solicitação de refúgio em território pátrio.

A lei nacional, porém, foi além, definindo como refugiado o indivíduo que devido a grave e generalizada violaçáo de direitos humanos, é obrigado a deixar seu país de nacionalidade para buscar refúgio em outro país. ${ }^{20} \mathrm{~A}$ definição legal de refúgio no Brasil, portanto, é mais ampla do que a disposta na Convenção Internacional.

Caetano, analisando a Lei de Refúgio Brasileira, afirma que:

O Estado brasileiro, a exemplo de outros do continente, adotou essa visão ao definir o refugiado como todo indivíduo que, devido à grave e generalizada violação de direitos humanos, é obrigado a deixar seu país de nacionalidade para buscar refúgio em outro país'- Lei 9.474/97.

A definição de refugiado, portanto, se apresenta elástica na mesma medida em que se agigantam os problemas e convulsóes de ordem econômica, social e política em diversos Estados e continentes do planeta. ${ }^{21}$

Ora, a previsão legal mais ampla que a disposta no tratado internacional garante o direito ao não rechaço, ou, na famosa expressão francesa, non-refoulement. Sobre o princípio do

19 PIOVESAN, F. O direito de asilo e a proteção internacional dos refugiados. In: ARAUJO, N. de; ALMEIDA, G. A. Refugiados: Realidade e Perspectivas. São Paulo. 2003, p. 113.

20 BRASIL. Lei no 9.474 , de 22 de julho de 1997. Define mecanismos para a implementaçáo do Estatuto dos Refugiados de 1951, e determina outras providências. Art. $1^{\circ}$, inciso III.

21 CAETANO, I. F. A Criança e o Adolescente Refugiados. Direitos Fundamentais. In: Revista Normatividade Jurídica. Série Aperfeiçoamento de Magistrados 11, p. 94. 
não rechaço:

Em sua definição, non-refoulement é um conceito que proíbe os Estados de devolverem um refugiado ou solicitante de refúgio para os territórios em que sua vida ou liberdade, bem como seus demais direitos fundamentais, estejam sob a ameaça de violação por questôes de raça, religiáo, nacionalidade, pertencimento a determinado grupo social ou opinião política [Grifos do autor]. ${ }^{22}$

Desta forma, impossível que um refugiado ou solicitante seja expulso, deportado ou repatriado (institutos de devolução previstos na nova Lei de Migração).

Importante observar que a recente vigência da Lei no 13.445/2017 não revogou a Lei de Refúgio Brasileira, tendo em vista que tal norma se limitou a prever outras hipóteses de autorização de residência, não regulamentando a concessão ou processamento do pedido de refúgio. A Lei de Migração prevê expressamente que:

Art. 20 Esta Lei não prejudica a aplicação de normas internas e internacionais específicas sobre refugiados, asilados, agentes e pessoal diplomático ou consular, funcionários de organização internacional e seus familiares. ${ }^{23}$

Isto posto, não se confunde o refúgio com quaisquer outros institutos previstos na Nova Lei Migratória, vez que o pedido de refúgio é tratado de forma autônoma e tem seu próprio regulamento no ordenamento jurídico brasileiro, qual seja, a Lei no 9.474 .

De todos os 49 artigos da supracitada lei, devemos dar destaque a dois pontos específicos. $\mathrm{O}$ primeiro deles diz respeito ao procedimento administrativo para o reconhecimento da condição de refugiado. A lei, em seu artigo 14 criou um o Comitê Nacional para os Refugiados (Conare), órgão de deliberação coletiva, vinculado ao Ministério da Justiça e com representantes de diversos órgãos ${ }^{24}$, responsável pela análise dos pedidos de refúgio feitos no Brasil. Da decisão do Conare, cabe recurso administrativo ao Ministro de Estado da Justiça, no prazo de quinze dias, conforme o art. 29 da Lei de Refúgio.

O segundo ponto de destaque para o presente estudo se relaciona com o protocolo do pedido de refúgio. Conforme os arts. 21 e 22:

22 OLIVEIRA, L. G. Barreiras fronteiriças contra o princípio de non-refoulement: a inacessibilidade do território e da determinação do status de refugiado. Revista Brasileira de Estudos Populares. Belo Horizonte, 2017, p. 33.

23 BRASIL. Lei no 13.445, de 24 de Maio de 2017. Institui a Lei de Migraçáo.

24 Conforme o art. 14 da Lei de Refúgio, o Conare é constituído por representantes do Ministério da Justiça; Ministério das Relaçôes Exteriores; Ministério do Trabalho; Ministério da Saúde; Ministério da Educação e do Desporto; Departamento de Polícia Federal; representante de organização não-governamental; e, como membro ouvinte, representante do Alto Comissariado das Naçóes Unidas para Refugiados (Acnur). 
Art. 21. Recebida a solicitação de refúgio, o Departamento de Polícia Federal emitirá protocolo em favor do solicitante e de seu grupo familiar que se encontre no território nacional, o qual autorizará a estada até a decisão final do processo.

$\$ 1^{\circ} \mathrm{O}$ protocolo permitirá ao Ministério do Trabalho expedir carteira de trabalho provisória, para o exercício de atividade remunerada no País.

$\$ 2^{\circ}$ No protocolo do solicitante de refúgio serão mencionados, por averbamento, os menores de quatorze anos.

Art. 22. Enquanto estiver pendente o processo relativo à solicitação de refúgio, ao peticionário será aplicável a legislação sobre estrangeiros, respeitadas as disposiçôes específicas contidas nesta Lei. ${ }^{25}$

Da exegese dos artigos citados, extrai-se as seguintes conclusóes: i) o simples protocolo do pedido de refúgio junto ao órgão competente dá direito provisório de permanência no Brasil, podendo o solicitante exercer plenamente seus direitos civis em território nacional, enquanto não há decisão definitiva de seu pedido; ii) o protocolo de solicitação de refúgio acaba por servir, na prática, de documento de identificação ao solicitante.

Daí a importância da solicitação de refúgio pelas crianças e adolescentes que se encontram no Brasil. A simples solicitação dará à criança ou ao adolescente a garantia de exercício de direitos básicos, tais como matrícula em escola; acesso à rede de saúde; acesso ao trabalho etc.

Importante observar que o aumento do número de solicitações de refúgio ${ }^{26}$ intensificou a atuação da Defensoria Pública da União em favor de imigrantes. Segundo Chiaretti ${ }^{27}$ :

Estes imigrantes e refugiados, em sua maioria, integram grupos extremamente vulneráveis. Por este motivo, a DPU tem procurado ampliar sua atuação para a tutela de imigrantes e refugiados, em especial na atuação extrajudicial, na orientação jurídica e na esfera coletiva. É neste cenário que o Grupo de Trabalho de Migrações e Refúgio ganha especial importância.

Por esta razão, apesar de não existir estatística oficial sobre a quantidade de atendimentos realizados, é notório que a Defensoria Pública da União tem orientado os imigrantes quanto à realização do pedido administrativo de refúgio junto ao Conare por intermédio da Polícia Federal, além de recorrer administrativamente das decisóes negativas do Comi-

\footnotetext{
25 BRASIL. Lei no 9.474, de 22 de julho de 1997. Estatuto dos Refugiados. Op. Cit. Arts. 21 e 22.

26 BAZZO, G.; REIS, T. Brasil aprovou 40\% das solicitaçóes de refúgio analisadas em 2017. 22/01/2018. Globo. Disponível em <https://g1.globo.com/mundo/noticia/brasil-aprovou-40-das-solicitacoes-de -refugio-analisadas-em-2017.ghtml $>$.

27 CHIARETTI, D. Refúgio, Migraçóes e os desafios da Defensoria Pública da União. In: Fórum DPU - Jornal da Escola Superior da Defensoria Pública da Uniáo, 2015, p. 05.
} 
tê, sem prejuízo da propositura de açóes junto ao Poder Judiciário. ${ }^{28}$

Tendo em vista a importância da atuação do órgão defensorial na temática, fica evidente que a DPU é a instituição que mais se depara com as dificuldades práticas apresentadas pelos solicitantes, incluindo a apresentação de pedidos por crianças e adolescentes sem o respectivo responsável legal.

\section{A RESOLUÇÁO CONJUNTA ENTRE CONARE, CONANDA, CNIG E DPU E A NATUREZA DA ATUAÇÃO DO DEFENSOR PÚBLICO FEDERAL}

Já disse Bobbio que "o problema fundamental em relação aos direitos do homem, hoje, não é tanto o de justifica-los, mas o de protege-los". ${ }^{29}$

A negativa por parte da Polícia Federal em aceitar a solicitação de refúgio por crianças e adolescentes desacompanhados levou ao Comitê Nacional para os Refugiados (Conare), o Conselho Nacional dos Direitos da Criança e do Adolescente (Conanda), o Conselho Nacional de Imigração (Cnig), e a Defensoria Pública da União (DPU), editar Resolução Conjunta a fim de garantir a proteção a estas pessoas.

A Polícia Federal partiu de uma interpretação literal e civilista da lei para chegar à conclusão de que as crianças e adolescentes não detém capacidade jurídica para realizar o pedido de refúgio.

É possível verificar a necessidade de criação de um procedimento em que a própria criança ou adolescente possam ser reconhecidos como refugiados independentemente da presença de seu representante legal. Identificando tal ausência no processo administrativo de refúgio brasileiro, Valle reconhece que:

É inegável que tais critérios para o status de refugiado, estabelecidos na Convenção de 1951, aplicam-se igualmente a crianças que visem a se beneficiar de tal status. Nesse sentido, o próprio artigo $22 \mathrm{da}$ Convençáo sobre os Direitos da Criança reforça que os Estados devem adotar medidas para assegurar o direito da criança de ser reconhecida

\footnotetext{
28 Sobre o tema, é posição da Defensoria Pública da União que a decisão de concessão ou não de refúgio não é discricionária, sendo dever do Poder Executivo a concessão sempre que verificada alguma das hipóteses legais ou convencionais. Neste sentido: "DIREITO INTERNACIONAL PÚBLICO. AÇÃO ORDINÁRIA. PEDIDO DE CONCESSÃO DE REFÚGIO. PERMANÊNCIA NO PAÍS. PROCEDÊNCIA. Caso em que a condição vivida pelo autor autoriza a concessão de refúgio porque é público e notório que o estado de Israel é constantemente palco de conflitos armados, sejam eles internos ou internacionais. Situação que gera a grave e generalizada violaçáo aos direitos humanos, uma vez que o permanente estado de tensão e medo a que estáo submetidos os moradores daquela região é incompatível com os direitos à vida e à segurança indispensáveis à existência digna" (Tribunal Regional Federal da 4a Região TRF-4 - APELAÇÃO/REEXAME NECESSÁRIO : APELREEX 303 PR 2008.70.00.000303-8).
} 
como refugiada, se preenchidos os requisitos para tanto conforme o direito internacional e/ou interno aplicável. Apesar dessa garantia, na maioria dos casos em que uma criança está acompanhada por seus pais ou responsáveis, a solicitação de refúgio é feita com base nas experiências destes, e não da criança. Se bem-sucedida a solicitação, o menor receberá o status de refugiado por derivação, com base no status de seus responsáveis. ${ }^{30}$

\title{
Continua a autora:
}

\begin{abstract}
Além de adequar o nível de violaçôes de direitos humanos às características da criança para melhor avaliar a existência de perseguição, os níveis de evidência também devem ser condizentes com a idade do solicitante de refúgio. Menores de idade por vezes não conseguem transmitir a situação que originou seu temor de perseguição de forma objetiva, com detalhes ou com a apresentação de documentos comprobatórios. $^{31}$
\end{abstract}

A citada resolução trouxe, enfim, procedimento específico a ser adotado nestes casos, de forma que o Estado brasileiro náo deixasse de promover a proteção deste grupo especialmente vulnerável.

Ressalte-se que a resolução vem ao encontro da proteção integral dada pelo Estatuto da Criança e do Adolescente (Lei no 8.069/1990) que não se aplica apenas às crianças e adolescentes brasileiros. O parágrafo único do art. $3^{\circ}$ da lei afirma expressamente que o estatuto é aplicado às crianças e adolescentes sem qualquer discriminação de nascimento, raça, etnia ou outra condiçáo que diferencie as pessoas, as famílias ou a comunidade em que vivem. ${ }^{32}$ Ainda, a Convenção Internacional sobre os Direitos da Criança, promulgada no Brasil através do Decreto no 99.710/1999, obriga os estados à concessão de refúgio à criança que dele necessitar. Em seu artigo 22:

1. Os Estados Partes adotarão medidas pertinentes para assegurar que a criança que tente obter a condiçâo de refugiada, ou que seja considerada como refugiada de acordo com o direito e os procedimentos internacionais ou internos aplicáveis, receba, tanto no caso de estar sozinha como acompanhada por seus pais ou por qualquer outra pessoa, a proteção e a assistência humanitária adequadas a fim de que possa usufruir dos direitos enunciados na presente convençáo e em outros instrumentos internacionais de direitos humanos ou de caráter humanitário dos quais os citados Estados sejam parte. ${ }^{33}$

Portanto, necessário que o Estado Brasileiro proteja integralmente e de forma prioritária

\footnotetext{
$30 \quad$ VALLE, Op. Cit., p. 5.

$31 \quad$ VALLE, Op. Cit., p. 6.

32 BRASIL. Op. Cit.

33 BRASIL. Decreto no 99.710, de 21 de Novembro de 1990. Promulga a Convençáo Sobre Direitos da Criança.
} 
este grupo hipervulnerável. O princípio da prioridade absoluta:

Estabelece primazia em favor das crianças e dos adolescentes em todas as esferas de interesses. Seja no campo judicial, extrajudicial, administrativo, social ou familiar, o interesse infanto-juvenil deve preponderar. Não comporta indagaçóes ou ponderaçóes sobre o interesse a tutelar em primeiro lugar, já que a escolha foi realizada pela nação através do legislador constituinte. ${ }^{34}$

Até a edição da resolução conjunta, é possível afirmar que o Brasil verdadeiramente descumpria o princípio da prioridade absoluta previsto na Constituição Federal e no ECA, bem como violava as disposiçóes da Convenção sobre Direitos da Criança, vez que dificultava a solicitação de refúgio por parte deste grupo migrante.

Em boa hora, portanto, que tais órgãos resolveram agir e implementar procedimento específico para tais casos.

A referida resolução é aplicável a dois grupos distintos: criança ou adolescente desacompanhado, aquele que náo possui nenhuma pessoa adulta acompanhando-lhe no seu ingresso em território nacional; e criança ou adolescente separado, aquele que está acompanhado por uma pessoa adulta que náo é o responsável legal que detenha poder familiar. ${ }^{35}$

A resolução trouxe relevantes atribuições aos membros da Defensoria Pública da União. Segundo seu art. 10:

Em continuidade ao processo de identificação, o membro da Defensoria Pública deverá iniciar entrevista, que deve ser conduzida de forma adequada à idade, sua identidade de gênero, deficiência, em uma linguagem que a criança e adolescente entendam, objetivando registrar sua história, incluindo, se possível, a identificaçáo dos pais e irmáos, bem como sua cidadania e a de pais e irmãos. [...]

A atuação da DPU não termina na entrevista. O artigo 12 da resolução traz ao Defensor Público Federal a necessidade de acompanhamento periódico da criança e adolescente:

A Defensoria Pública da União será responsável pelos pedidos de regularização migratória, solicitação de documentos e demais atos de proteçáo, como o preenchimento de "Formulário para análise de proteção" (Anexo I), bem como acompanhar a criança e adolescente desacompanhados ou separados nos procedimentos subsequentes à sua identificação preliminar.

34 AMIN, A. R. Princípios Orientadores do Direito da Criança e do Adolescente. In: MACIEL, Kátia (Org.). Curso de Direito da Criança e do Adolescente: Aspectos Teóricos e Práticos, 2010, p. 20.

35 BRASIL. Resoluçáo conjunta Conanda, Conare, CNIg e DPU. 09 de agosto de 2017. Art. 1º, $\$ 1^{\circ}$. 
Analisando os artigos 10 e 12 da resolução, é impossível afirmar que a atuação do Defensor Público é a mesma de um advogado particular. Trata-se, na verdade, de atuação atípica do órgão em razão do necessário acompanhamento da DPU em favor da criança ou adolescente.

Ora, é possível a intervenção da Defensoria Pública nestes termos? Pode o Defensor Público atuar de forma extrajudicial com tamanha profundidade?

A resposta é positiva.

Conforme já demonstrado no primeiro item deste artigo, a Defensoria Pública já não mais atua somente como um advogado para quem não tem condiçóes de custear um particular. O órgão se tornou verdadeiro protetor dos direitos humanos, incluídos nestes, os direitos das crianças e adolescentes. De fato, não há órgão estatal melhor do que a Defensoria Pública para o acompanhamento das crianças e adolescentes desacompanhados, seja em razão de sua missáo constitucional, seja em razáo da experiência destes agentes públicos no trato de grupos vulneráveis.

Ora, se, interpretando a resolução, a Defensoria Pública não atua como simples mandatário jurídico da criança ou adolescente, qual a natureza jurídica de sua atuação?

É sabido que o Novo Código de Processo Civil trouxe importante avanço processual ao consolidar nas máos da Defensoria Pública a atuaçáo como Curadora Especial de incapazes. Segundo o novel diploma processual:

Art. 72. O juiz nomeará curador especial ao:

I - incapaz, se não tiver representante legal ou se os interesses deste colidirem com os daquele, enquanto durar a incapacidade;

II - réu preso revel, bem como ao réu revel citado por edital ou com hora certa, enquanto não for constituído advogado.

Parágrafo único. A curatela especial será exercida pela Defensoria Pública, nos termos da lei. ${ }^{36}$

É perceptível a proximidade de institutos quando comparamos a atuação da Defensoria Pública como curadora especial, conforme o disposto no Código de Processo Civil, com a intervenção em favor das crianças e adolescentes desacompanhados.

Nos dois casos a Defensoria Pública atua em favor de incapazes sem representante legal.

Acontece que a curatela especial em favor de incapazes que náo tenham representante legal se limita à atuaçáo processual em favor do representado.

36 BRASIL. Lei no 13.105, de 16 de março de 2016. Código de Processo Civil. Art. 72. 
Neste sentido, o Tribunal de Justiça do Rio de Janeiro já decidiu que "O Curador Especial" é um representante processual, dotado de capacidade postulatória, nomeado para suprir a incapacidade processual da parte $[\ldots] .^{37}$

Analisando a resolução, não há que se falar em identidade de institutos entre o regulamentado e o disposto no Código de Processo Civil. Enquanto a curatela especial visa a promoção do contraditório e ampla defesa no âmbito processual, a atuação da Defensoria Pública em favor de crianças e adolescentes desacompanhados vai muito mais além.

Não se trata de simples representação em processo administrativo. O Defensor Público Federal deverá, entre outros, avaliar a vulnerabilidade, saúde física, psicossocial e necessidades de proteção (art. 11, inciso II); recolher informaçôes sobre finalidades relacionadas à exploração sexual, adoção ilegal, tráfico de pessoas, submissão a qualquer tipo de servidão ou situaçấo análoga à de escravo, ou remoção de órgãos (art. 11, inciso III); acionar representante da Defensoria Pública do Estado para atuação em âmbito estadual (art. 12, $\$ 1^{\circ}$ ); praticar atos de proteção e garantias de direitos (art. 16).

Assim, a intervenção da Defensoria Pública da União em favor de crianças e adolescentes desacompanhados se revelou forma inédita de atuação, que não se confunde com a simples curatela especial processual.

Trata-se, em verdade, de elevação da Defensoria Pública como verdadeira instituição promotora de proteção dos direitos individuais de cada criança ou adolescente que se encontra nesta situação, revelando-se uma atuação atípica e sui generis.

Apesar disto, esta atuação se mostra plenamente justificável e embasada nas atribuiçóes da Defensoria Pública como protetora dos direitos humanos e como instituição responsável pela garantia de direitos das crianças e adolescentes.

\section{CONSIDERAÇÓES FINAIS}

A atuação da Defensoria Pública da União em favor de crianças e adolescentes desacompanhados não se confunde com a mera representação jurídica processual. Ainda, não se trata de curatela especial exercida pelo Defensor Público responsável.

A resoluçáo conjunta entre o Conanda, Conare, CNIg e DPU trouxe ao ordenamento jurídico espécie inédita de intervenção da Defensoria Pública em favor de um grupo hipervulnerável. Se, de um lado, temos que a atuação da Defensoria se dá de maneira

37 BRASIL. Tribunal de Justiça do Rio de Janeiro. Processo TJ-RJ Agravo de Instrumento 0006641-48.2013.8.19.0000. Data de publicação: 16/08/2013. Órgão Julgador: 9o Câmara Cível. Relator: Des. Rogério de Oliveira Souza. 
ímpar, de outro, podemos, sem sombra de dúvida, afirmar que esta possibilidade está em plena consonância com as atribuiçóes institucionais do órgáo defensor, bem como com os tratados internacionais sobre o tema.

Ora, nada mais lógico do que dar tais poderes de proteção ao órgão que tem por missão constitucional a garantia dos direitos humanos.

A referida resolução demonstra o avanço no reconhecimento da Defensoria Pública como instituição responsável à proteção de direitos das crianças e adolescentes, sendo verdadeira conquista da instituição para a plena garantia de direitos dos grupos vulneráveis, servindo, inclusive, como verdadeiro exemplo de diploma jurídico que reconhece a forma atual da Defensoria Pública.

Temos que, assim como a resolução fez, o ordenamento jurídico pátrio deve se adaptar à nova face constitucional da Defensoria Pública: instituição nacional garantidora de direitos humanos e protetora de grupos vulneráveis, abrindo mão da antiga e arcaica visão de simples advogado do pobre.

\section{REFERÊNCIAS}

AMIN, A. R. Princípios Orientadores do Direito da Criança e do Adolescente. In: MACIEL, K. (Org.). Curso de Direito da Criança e do Adolescente: Aspectos Teóricos e Práticos. 4a Ed. Rio de Janeiro: Lumen Juris. 2010.

BARROS, G. F. de M. Defensoria Pública: Comentários à LC no 80/1994. 5a edição. 2013.

BASTOS, C. E. C.; GARCIA, M. Judiciário pode rever decisão que deu refúgio a Battisti. 10 de março de 2009. Disponível em <https:/www.conjur.com.br/2009-mar-10/ judiciario-rever-decisao-ministerial-deu-refugio-battisti>. Acesso em: 04 de fevereiro de 2018.

BAZZO, G.; REIS, T. Brasil aprovou $\mathbf{4 0} \%$ das solicitaçóes de refúgio analisadas em 2017. 22/01/2018. Globo. Disponível em: <https://g1.globo.com/mundo/noticia/ brasil-aprovou-40-das-solicitacoes-de-refugio-analisadas-em-2017.ghtml>.Acesso em: 04/02/2018.

BOBBIO, N. A Era dos Direitos. Trad. Carlos Nelson Coutinho. $8^{\text {a }}$ Ed. Rio de Janeiro: Campus, 1992.

BRASIL. Conselho Nacional do Ministério Público. Relatório da Pesquisa de Satisfação e Imagem do CNMP e do Ministério Público - 2017. Julho de 2017.

BRASIL. Constituição da República Federativa do Brasil. 1988.

BRASIL. Decreto no 50.215, de 28 de janeiro de 1961. Promulga a Convençáo relativa 
ao Estatuto dos Refugiados, concluída em Genebra, em 28 de julho de 1951.

BRASIL. Decreto no 70.946 de 7 de agosto de 1972. Promulga o Protocolo Sobre o Estatuto dos Refugiados.

BRASIL. Decreto no 99.710, de 21 de Novembro de 1990. Promulga a Convençáo Sobre Direitos da Criança.

BRASIL. Defensoria Pública da União. Anuário de Atuaçáo Coletiva da Defensoria Pública da Uniáo. Abril 2017 - Maio 2018. 2018.

BRASIL. Lei Complementar no 80, de 12 de Janeiro de 1994. Organiza a Defensoria Pública da União, do Distrito Federal e dos Territórios e prescreve normas gerais para sua organizaçấo nos Estados, e dá outras providências.

BRASIL. Lei no 13.105, de 16 de março de 2016. Código de Processo Civil.

BRASIL. Lei no 13.445, de 24 de Maio de 2017. Institui a Lei de Migraçáo.

BRASIL. Lei no 8.069, de 13 de julho de 1990. Dispóe sobre o Estatuto da Criança e do Adolescente e dá outras providências.

BRASIL. Lei no 9.474, de 22 de julho de 1997. Define mecanismos para a implementação do Estatuto dos Refugiados de 1951, e determina outras providências.

BRASIL. Resoluçáo conjunta Conanda, Conare, CNIg e DPU. 09 de agosto de 2017.

BRASIL. Sítio oficial da Defensoria Pública da União. Disponível em http://dpu.def. br/endereco-sao-paulo\#faqnoanchor. Acesso em 04 de fevereiro de 2018.

BRASIL. Tribunal de Justiça do Rio de Janeiro. Processo TJ-RJ Agravo de Instrumento 0006641-48.2013.8.19.0000. Data de publicação: 16/08/2013. Órgão Julgador: 9 Câmara Cível. Relator: Des. Rogério de Oliveira Souza.

CAETANO, I. F. A Criança e o Adolescente Refugiados. Direitos Fundamentais. In: Revista Normatividade Jurídica. Série Aperfeiçoamento de Magistrados 11.

CHIARETTI, D. Refúgio, Migrações e os desafios da Defensoria Pública da União. In: Fórum DPU - Jornal da Escola Superior da Defensoria Pública da União. $4^{\circ}$ Trimestre de 2015. Ed. No 3, ano 1.

MARTUSCELLI, P. N. A Proteção Brasileira para crianças refugiadas e suas consequências. In: REMHU: Revista Interdisciplinar da Mobilidade Urbana, vol. 22, no 42, Brasília. 2014.

OLIVEIRA, L. G. Barreiras fronteiriças contra o princípio de non-refoulement: a inacessibilidade do território e da determinação do status de refugiado. Revista Brasileira de Estudos Populares. Belo Horizonte. Vol. 34. No 1. 2017. 
PIOVESAN, F. O direito de asilo e a proteção internacional dos refugiados. In: ARAUJO, N. de; ALMEIDA, G. A. Refugiados: Realidade e Perspectivas. São Paulo. 2003.

RAMOS, A. de C. Curso de Direitos Humanos. São Paulo. Saraiva: 2014.

REIS, R. R.; MENEZES, T. S. Direitos Humanos e refúgio: uma análise sobre o momento anterior à determinação do status de refugiado. In: Revista de Sociologia e Política. Vol. 22. No 49. Curitiba. Janeiro-Março. 2014.

SARMENTO, D. Parecer: Dimensões Constitucionais da Defensoria Pública da União. Rio de Janeiro, 2015.

VALLE, M. F. V. O Processo de Refúgio no Brasil e a Proteção à Criança Solicitante de Refúgio. In: Revista Eletrônica de Direito Internacional. Edição Especial - Refugiados. Vol. 20. 2017. 